Sharif University of Technology
Scientia Iranica
SCIENTIA
I RAN I C A
http://scientiairanica.sharif.edu

\title{
Effect of damped outriggers arrangement on the seismic response of high-rise steel structures
}

\author{
H. Asadi Ghoozhdi and M. Mofid* \\ Department of Civil Engineering, Sharif University of Technology, Tehran, Iran.
}

Received 1 July 2017; received in revised form 4 April 2018; accepted 2 July 2018

\author{
KEYWORDS \\ Damped outrigger; \\ Viscous damper; \\ Outriggers \\ arrangement; \\ High-rise steel \\ structures; \\ Inelastic dynamic \\ time-history analysis.
}

\begin{abstract}
Recently, a novel structural system, which is defined as a damped outrigger system, has been proposed to control the dynamic vibration of tall buildings. This paper examines the seismic performance of tall buildings involving multiple outriggers equipped with viscous dampers. In this respect, a dual structural system (braced moment frame) is selected as a bare structure. In addition, the number and position of outriggers are assumed to be variable along the structure height. Nonlinear Response History Analysis (RHA) is performed to evaluate the efficiency of the damped-outrigger system under eight-scaled ground motions. The results are presented based on the average of all ground motions. The mean inter-story drift ratio and maximum base shear force are compared in order to determine the best arrangement of damped outriggers. Conclusively, based on minimizing base shear force, the optimal location of damped outriggers under dynamic excitation is generally the same as that made for conventional outriggers. According to the inter-story drift ratio parameter, it is recommended to place one of the outriggers at the roof level.
\end{abstract}

(C) 2020 Sharif University of Technology. All rights reserved.

\section{Introduction}

The construction of towers and tall buildings has been favored among humankind from the beginning of civilization. The purpose of the first towers, like castles, was to defend cities. In the 19th century, the development of high-rise structures was a solution to commercial and residential needs [1].

Since the 1970s, outrigger systems have been often used in tall buildings [2]. This system includes two types of structural systems: the first type is a central core such as steel braced frame, steel shear wall,

\footnotetext{
*. Corresponding author. Tel.: +982166164214; Fax: +982166014828

E-mail addresses: hamid.asadi1990@gmail.com (H. Asadi Ghoozhdi); mofid@sharif.edu (M. Mofid)
}

doi: $10.24200 /$ sci. 2018.20691 concrete core, and concrete shear wall. The second type is an outrigger system such as girders and truss that connects the central core to the perimeter columns. The optimum position of the outrigger system is a major challenge for structural engineers. Furthermore, architectural limitations should be considered. As a common solution, outriggers are placed at stories with mechanical equipment. An outrigger system is usually applied to two sequential stories in order to increase the lateral stiffness of tall buildings $[1,2]$.

Damping is a major factor in controlling the vibration of tall buildings located in seismic regions. Based on recent investigations of different buildings, the damping ratio of tall buildings is lower than that of the others. Moreover, damping ratio depends on the amplitude of earthquake to the point that increasing the intensity of earthquake provides a higher damping level [3]. In addition, the analysis and design of tall buildings should be performed at several levels 
of ground motion intensity. By using an appropriate device as an additional damping source, it is feasible to achieve higher damping levels. Subsequently, the materials used in the structural elements may be reduced [4].

To improve the structural performance of the outrigger system, the location and number of outriggers should be adjusted. The optimum location has been computed mainly under the static condition. There are few references available to the dynamic response of outrigger systems. For uniform lateral loading and considering rigid outriggers, the optimum location has been computed in several cases. In the one-outrigger case, the optimum location was at $0.455 H$ from the top of the structure, where $H$ is the height of the cantilever model [5]. For a uniform cantilever beam equipped with two rigid outriggers, optimum locations were at $0.312 H$ and $0.685 H$ from the top, where $H$ is characterized by the same definition [6]. The response of the outrigger system with variable stiffness of the cantilever model along the height of a structure was studied under several lateral load distributions. It was concluded that the location of outrigger in the vicinity of the base level was not efficient enough. Besides, the effect of lateral load distribution on the outrigger position was negligible [7]. In another study, the influence of outrigger flexibility with regard to the best position of the multi-outrigger system subjected to uniform lateral loading was discussed. In addition, the effect of outrigger flexibility relevant to various structural parameters such as core moment distribution, top drift, and optimal position was investigated. The more flexible the outriggers are, the lower the optimum position will be. In addition, the application of outrigger systems with lower rigidity caused a considerable reduction in structural efficiency [8]. Optimal design of high-rise structures equipped with multiple conventional outriggers was investigated under two prevalent lateral load distributions. Furthermore, variations of some structural parameters such as the fundamental period of structure versus the location of outriggers were achieved. It was found that the optimum location of outriggers in tall buildings subjected to uniform lateral loading was approximately $5 \%$ lower than that of structures subjected to triangular lateral load distributions [9].

In recent years, damped outrigger systems have been proposed for tall buildings. This structural form is introduced as a new philosophy to control the induced vibration in tall buildings. Based on this concept, the application of damped outriggers may lead to higher levels of damping. In this system, a combination of outriggers and viscous dampers can be applied in several ways. For instance, a viscous damper can be connected to the end of outriggers or located in them. To evaluate the efficiency of the damped outrigger, two actual buildings were considered. It was concluded that the additional damping ratio of those structures subjected to a 100-year wind vibration was estimated between $5.2 \%$ and $11.2 \%$ for each principal direction. Consequently, the amount of structural material reduced and the net area of each story increased [10].

The efficiency of damped outrigger systems was also verified through an experimental study. This investigation showed that the amount of supplementary damping increased through the addition of viscous dampers at the end of outriggers. By performing a test with a shaking table, the seismic performance of an eight-story steel structure with multiple outriggers was investigated for two cases. In the first case, the connections between outriggers and perimeter columns were pinned, whereas outriggers were equipped with viscous dampers in the second case. It was found that the efficiency of viscous damper under moderate earthquakes was nearly equal to the bare structures. However, as earthquake intensity increased, the influence of viscous damper became more obvious [11].

A simplified model was suggested for assessing the seismic behavior of tall buildings equipped with hysteresis damped outriggers. The effect of outriggers on the central core was considered based on the applied concentrated moments [12]. A simple beam-damper model was developed to obtain an exact solution for damped outrigger systems. Furthermore, this includes a cantilever beam and a rigid horizontal element model as the main structure and the outrigger, respectively. The outrigger was connected to the cantilever beam by using viscous dampers. Dynamic characteristics of the model were computed based on the analytical solution. Thus, the optimal location of the damped outrigger and the optimum value of damping coefficient were determined [13]. The cantilever beam model was improved by considering the effect of axial stiffness of perimeter columns [14]. A general solution for the performance evaluation of tall buildings with multiple damped and conventional outriggers was presented. As for the results of a tall building with multiple damped or undamped outriggers, the proposed method was capable of providing an optimally parametric design with respect to the position of outriggers, damping, and core-to-column and core-to-outrigger stiffness ratios [15]. Huang and Takeuchi obtained an analytical solution for the dynamic response evaluation of a single-damped-outrigger system and determined the optimal outrigger locations and damper sizes to minimize the response. The optimal outrigger location was between $0.5 H$ and $0.8 H$ from the base. Besides, the optimum values of outrigger location and damper size increased with building height [16]. The seismic energy distribution through the core and outriggers of a 60 story building with conventional and damped outriggers was examined under small, moderate, strong, and 
severe long-period earthquakes. It was revealed that as the ground motion became stronger, viscous dampers effectively reduced the potential of damage to the structure compared to the conventional outriggers [17].

To increase the damping of the outrigger system, other passive energy dissipators, such as BucklingRestrained Brace (BRB), are also implemented [1821]. This element limits the maximum force that the outrigger can develop [18]. It was observed that the location of the plastic hinges in the core wall was influenced by the BRB outriggers [20]. Moreover, a response modification factor of 5 is recommended for the Reinforced Concrete (RC) core-wall with BRB [21].

Most of the above-mentioned studies have mainly focused on the linear systems. Moreover, these investigations are commonly limited to single outrigger structures. In this paper, the seismic response of tall buildings involving multiple damped outriggers is studied. Two important parameters, the number and location of outriggers, are considered to examine the performance of a damped-outrigger system. To this end, a dual structural system consists of a moment frame, and a braced core has been selected as the reference model. These steel frames are modeled with geometric and material nonlinear behaviors. Moreover, by including outriggers, two general cases are considered. It should be noted that the position of outriggers varies along the height of the structure. In addition, the number of outriggers is assumed to be one, two or three. Nonlinear time-history analysis is carried out to assess the performance of the damped-outrigger system. These structures' responses including maximum story drift and maximum base shear force are compared to determine the best position of outriggers.

\section{Description of the models}

\subsection{Preliminary design}

Three structural models featuring 20,30, and 40 stories are considered to evaluate the seismic performance of damped outrigger systems. These models are twodimensional, regular, and interior frames. The eleva- tion view of the models is depicted in Figure 1. A dual structural system, which includes a moment frame and a braced core, has been selected. A preliminary design of steel bare structures (without outrigger) is performed according to the Iranian Code of Practice for Seismic-Resistant Design of Buildings (Standard No. 2800) and the Iranian National Building Codes (Parts 6 and 10). Furthermore, the design of steel frames is performed based on the Load and Resistance Factor Design (LRFD) method mentioned in AISCLRFD 2010 [22] and AISC 341-10 [23]. Therefore, the effect of outriggers in the initial design of structural members has been ignored. As seen in Figure 2, interstory drift limits may not be satisfied in the bare structures under linear response spectrum analysis. In the preliminary design, this defection will be improved by the appropriate arrangement of damped outriggers. The aim of this paper is to obtain the best solution to this problem.

The structural frames have bays with an equal

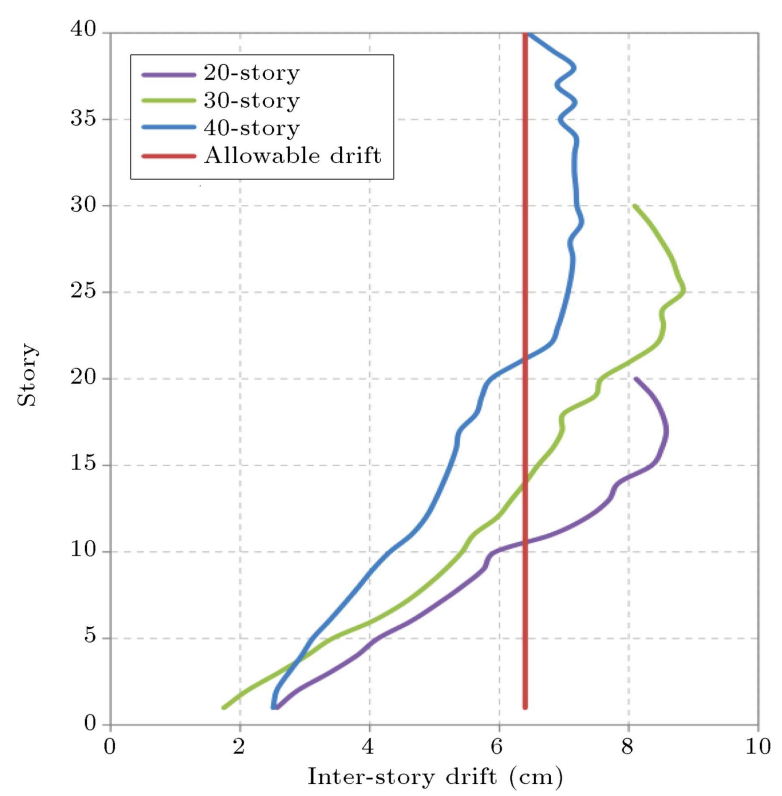

Figure 2. Inter-story drift values of structures under preliminary design.
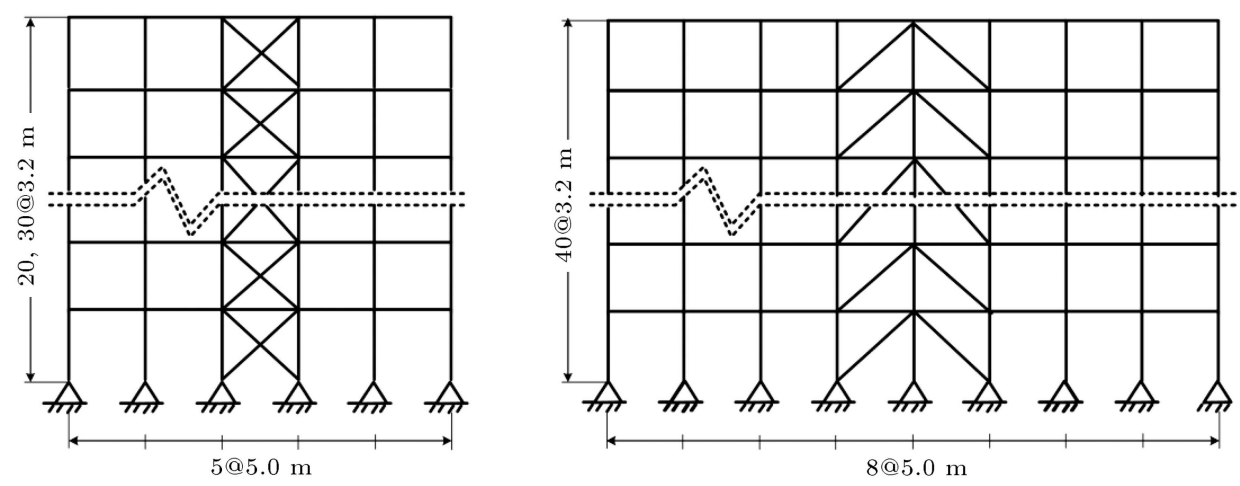

Figure 1. Schematic plot of studied structures. 
width of $5 \mathrm{~m}$ and a typical height of $3.2 \mathrm{~m}$ in each story. The structures are assumed to be located in Tehran, which is a highly seismic region (with zone design acceleration corresponding to 475 years return period, $A=0.35$ ) on soil type $\mathrm{C}$ according to NEHRP classification. The gravity loads are $7.5 \mathrm{kN} / \mathrm{m}^{2}$ and $2.5 \mathrm{kN} / \mathrm{m}^{2}$ for dead and live loads, respectively. The effective seismic mass of the structure is considered to be dead load plus $20 \%$ of the live load. The fully restrained beam-to-column connections in steel momentresisting frames are considered. In addition, nonlinear beam-column elements with pinned end connections are applied for the braces. The box profiles are selected for columns and braces, and European wide flange sections are used for beams. The sections of structural components are shown in Table 1.

\subsection{Nonlinear modeling}

In order to investigate the seismic responses of structures equipped with damping systems, according to the ASCE/SEI 7-10 [24] recommendation, the nonlinear response history procedure is suggested. For this purpose, high-rise structures with damped outriggers should be modeled with nonlinear material behavior. Elastic-linearly plastic behavior is utilized for steel material. Properties of steel are defined with a yield stress of $235 \mathrm{MPa}$, an initial elastic modulus of $200 \mathrm{GPa}$, and a strain-hardening ratio equal to $2 \%$. The 'Steel01' material, which is defined in the library of Open System for Earthquake Engineering (OpenSees) platform [25], is used to model the behavior of steel material.

Braces, beams, and columns have been modeled with the force-based beam-column element in the OpenSees framework. The formation of plastic hinges is captured through the fiber modeling approach (distributed plasticity). The beams and columns of the structure are modeled with a single force-based beamcolumn element. Five integration points along the member length are considered, and each section at the beam-column ends is discretized to 200 fibers. Lateral buckling of the brace elements has been applied by considering an initial imperfection for the braces. Based

Table 1. Properties of designed structures.

\begin{tabular}{|c|c|c|c|c|}
\hline Model & Story & Beams & Columns (mm) & Braces (mm) \\
\hline \multirow[t]{4}{*}{20 -story } & $1-5$ & HEB 26 & Box $500 \times 25$ & Box $150 \times 10$ \\
\hline & $6-10$ & HEB 26 & Box $400 \times 20$ & Box $150 \times 10$ \\
\hline & $11-14$ & HEB 20 & Box $300 \times 15$ & Box $150 \times 8$ \\
\hline & $15-20$ & HEB 20 & Box $200 \times 10$ & Box $150 \times 8$ \\
\hline \multirow[t]{7}{*}{30 -story } & $1-5$ & HEB 26 & Box $600 \times 30$ & Box $200 \times 10$ \\
\hline & $6-11$ & HEB 26 & Box $500 \times 25$ & Box $150 \times 10$ \\
\hline & $12-15$ & HEB 26 & Box $400 \times 20$ & Box $150 \times 10$ \\
\hline & $16-18$ & HEB 26 & Box $400 \times 20$ & Box $150 \times 8$ \\
\hline & $19-20$ & HEB 20 & Box $300 \times 15$ & Box $150 \times 8$ \\
\hline & $21-25$ & HEB 20 & Box $300 \times 15$ & Box $150 \times 8$ \\
\hline & $26-30$ & HEB 20 & Box $200 \times 10$ & Box $150 \times 8$ \\
\hline \multirow[t]{7}{*}{ 40-story } & $1-5$ & HEB 26 & Box $700 \times 40$ & Box $200 \times 10$ \\
\hline & $6-10$ & HEB 26 & Box $600 \times 30$ & Box $200 \times 10$ \\
\hline & $11-17$ & HEB 26 & Box $500 \times 25$ & Box $150 \times 10$ \\
\hline & $18-22$ & HEB 26 & Box $400 \times 20$ & Box $150 \times 10$ \\
\hline & $23-28$ & HEB 26 & Box $400 \times 20$ & Box $150 \times 8$ \\
\hline & $29-34$ & HEB 20 & Box $300 \times 15$ & Box $150 \times 8$ \\
\hline & $35-40$ & HEB 20 & Box $200 \times 10$ & Box $150 \times 8$ \\
\hline
\end{tabular}


on the recommendations made by Uriz and Mahin [26], parameters needed for modeling steel brace are specified (including the number of segments, integration points, and value of initial camber). Accordingly, each brace element is modeled by subdividing its length into 2 force-based fiber elements in order to contemplate the simplest initial imperfection curve. The initial imperfection is assumed to be $0.1 \%$ of the member length in the middle of brace element in this study. It should be noted that the number of integration points and fibers selected for brace elements is the same as that used for beam-column members.

\subsection{Inherent damping}

Damping is a structural factor to evaluate the amount of energy dissipated by the structure. This parameter causes a considerable reduction in the dynamic vibration of tall buildings. There are three sources to provide damping: inherent, hysteretic, and additional damping. Inherent damping depends on some characteristics of the building itself such as foundation, structural system, material, non-structural components, and cladding. Moreover, the height of buildings plays a significant role in the level of damping that contributes to the structural response. According to these factors, determining inherent damping is complicated [4]. Hysteretic damping is the primary source of damping developed through the formation of plastic hinges at member ends. The third source that is defined by adding a device to the building is supplementary damping. In this paper, the effect of supplementary damping on the behavior of structures is modeled explicitly. Section 2.4 of PEER/ATC-72-1 [3] puts forward some recommendations for modeling the material damping. Measurements indicate that damping value in tall buildings is lower than that in low-rise structures, as illustrated in Figure 3. Therefore, using classic damping ratios suggested by available guidelines and codes is non-conservative. In line with the following recommendations for the damping ratio of high-rise steel structures in Figure 3, this value is determined.

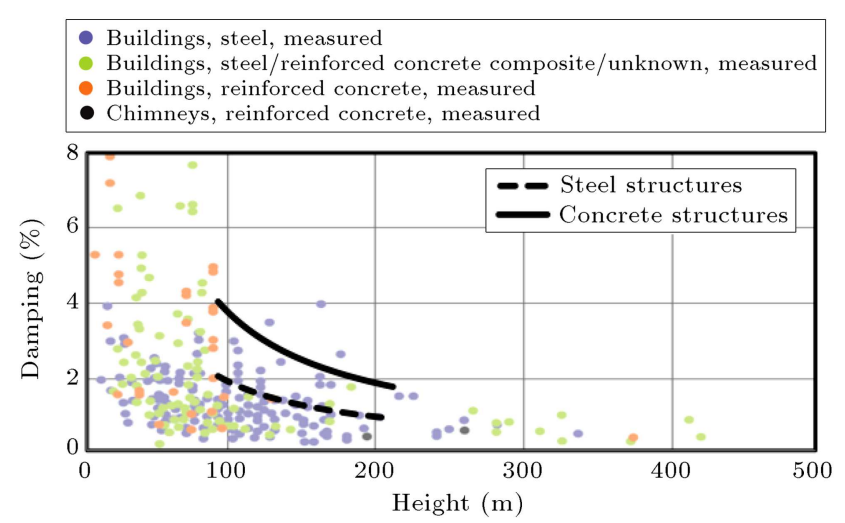

Figure 3. Proposed damping ratio for tall buildings $[3,4]$.
Note that this damping ratio is suggested for nonlinear response history analyses. Through the application of Rayleigh method, the material damping is assigned to the first mode and the mode in which the cumulative mass participation is at least $90 \%$.

\subsection{Verification of linear structures}

By a modal analysis, fundamental periods of structures are presented in Table 2. Modal analysis is established by finite element programs (SeismoStruct [27] and OpenSees). It must be mentioned that the fundamental period of vibration is determined without considering the effect of outriggers. In other words, these periods are related to bare structures. It can be found that the models' periods computed based on two computer programs are the same. Therefore, the linear models constructed in OpenSees framework are verified.

\section{Ground motion excitations}

\subsection{Selection of the earthquake records}

The ground motions selected in this study include eight earthquake records. These records are chosen from the earthquake excitations mentioned in Appendix- $\mathrm{C}$ of FEMA 440 [28] and Appendix-A of FEMA P695 [29]. Furthermore, the proposed records are related to the site class $\mathrm{C}$ according to the NEHRP site classification (average shear wave velocity in the top $30 \mathrm{~m}$ : 360$760 \mathrm{~m} / \mathrm{s}$ ). In addition, the station selected for each earthquake is related to a far-field record. Thus, Table 3 shows an ensemble of eight ground motions used in the nonlinear Response History Analysis (RHA). In this table, scaling factors of the ground motions are given based on the technique presented in Section 3.2. Earthquake records were obtained from the PEER ground motion database [30].

\subsection{Scaling the earthquake records}

According to the ASCE/SEI 7-10 standard, records should be scaled in a way that the design response spectrum for the site class $\mathrm{C}$ does not get greater than the average of the acceleration spectra for the ground motions. Periods ranging from $0.2 T$ to $1.5 T$ must be controlled, where $T$ is the fundamental period of the structure. The comparison between the mean linear response spectrum of the eight ground motion and the target spectrum is shown in Figure 4; the pseudo-

Table 2. Fundamental period of structures.

\begin{tabular}{|c|c|c|}
\hline \multirow[b]{2}{*}{ Model } & \multicolumn{2}{|c|}{$\begin{array}{c}\text { Fundamental period of } \\
\text { vibration (sec) }\end{array}$} \\
\hline & SeismoStruct & OpenSees \\
\hline 20 -story & 2.44 & 2.39 \\
\hline 30-story & 3.61 & 3.57 \\
\hline 40-story & 4.10 & 4.02 \\
\hline
\end{tabular}


Table 3. Properties of ground motion records.

\begin{tabular}{cccccccc}
\hline Earthquake name & Date & $\mathbf{M s}$ & $\begin{array}{c}\text { Station } \\
\text { name }\end{array}$ & $\begin{array}{c}\text { Epicenter } \\
\mathbf{( k m )}\end{array}$ & $\begin{array}{c}\text { Component } \\
(\mathbf{d e g})\end{array}$ & $\begin{array}{c}\text { PGA } \\
(\mathbf{g})\end{array}$ & $\begin{array}{c}\text { Scaled PGA } \\
(\mathbf{g})\end{array}$ \\
\hline Hector Mine & 1999 & 7.1 & Hector & 26.5 & 90 & 0.34 & 0.49 \\
Kobe & 1995 & 6.9 & Nishi-Akashi & 8.7 & 0 & 0.51 & 0.53 \\
Manjil & 1990 & 7.4 & Abbar & 40.4 & TR & 0.50 & 0.50 \\
Loma Prieta & 1989 & 7.1 & Saratoga & 27.2 & 0 & 0.51 & 0.54 \\
Loma Prieta & 1989 & 7.1 & Gilory & 29.0 & 67 & 0.36 & 0.55 \\
Northridge & 1994 & 6.8 & Castaic & 40.7 & 360 & 0.51 & 0.51 \\
Morgan Hill & 1984 & 6.1 & Gilory \#6 & 36.3 & 90 & 0.29 & 0.50 \\
Tabas & 1978 & 6.9 & Dayhook & 20.6 & TR & 0.41 & 0.55 \\
\hline
\end{tabular}

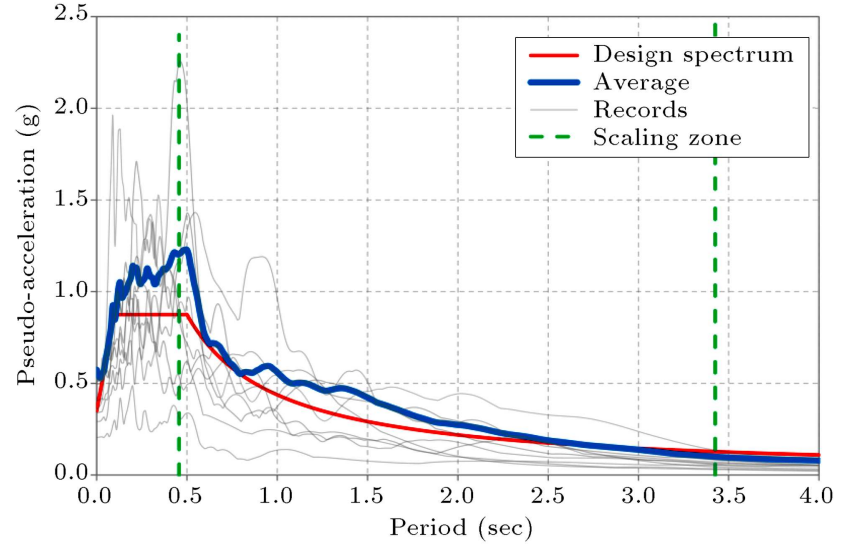

Figure 4. Acceleration response spectrum of the scaled ground motion records.

acceleration response spectrum of the ground motion is determined.

\section{Specifications of damped outriggers}

\subsection{Configuration of damped outriggers}

The components of damped outriggers in each structural model are shown in Figure 5. Basically, the outrigger set is located at two adjacent stories and consists of a steel brace element and a viscous damper. Bracing members used in the outrigger system are modeled similarly to braces of the reference structure. Therefore, the possibility of lateral buckling for these elements has been also investigated using the method mentioned in Section 2.1.

Viscous damper is a type of viscoelastic damping systems. These devices are installed between two specific points of the structure and work based on the relative velocity of the points. Viscous dampers are installed as diagonal braces at peripheral bays. The central braced core is connected to viscous dampers by steel bracing members. The damper system is modeled by using Maxwell material. This model includes a viscous damper and a spring connected in series. Spring element represents the elastic stiffness of the link used to install the viscous damper in the target frame.

\subsection{Determination of damped outrigger parameters}

It is essential to compute the effective parameters of damped outrigger system before evaluating the impact of outrigger location on the response of tall buildings. For this reason, characteristics of the brace element, as well as the viscous damper, should be obtained. In the one-outrigger case, the outrigger is placed at mid-height in order to determine the properties of the damped outrigger. In other cases, the first outrigger is fixed at middle stories, and the second one is located

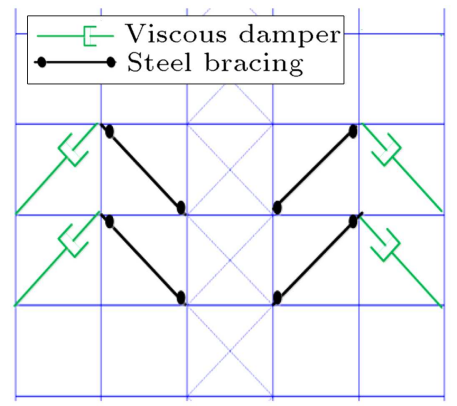

20 -story and 30-story structures

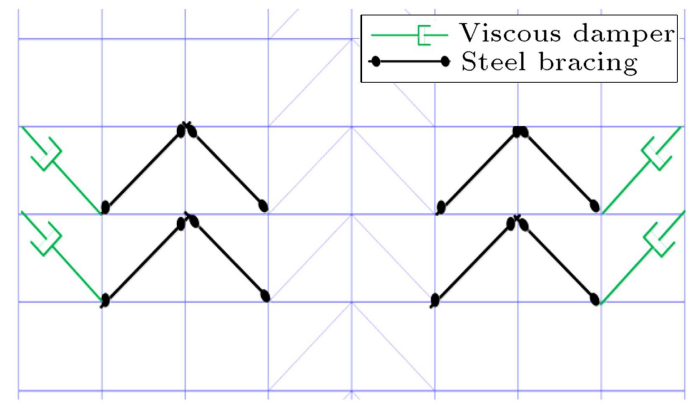

40-story structures

Figure 5. Schematic plots of damped outrigger system configuration. 
Table 4. Characteristics of damped outrigger components.

\begin{tabular}{|c|c|c|c|c|}
\hline \multirow[b]{2}{*}{ Model } & \multirow[b]{2}{*}{ No. of outriggers } & \multicolumn{2}{|c|}{ Viscous damper } & \multirow[b]{2}{*}{$\begin{array}{c}\text { Bracing } \\
(\mathrm{mm})\end{array}$} \\
\hline & & $\begin{array}{l}\text { Stiffness } \\
(\mathrm{kN} / \mathrm{m})\end{array}$ & $\begin{array}{c}\text { Damping coefficient } \\
(\mathrm{kN} . \sec / \mathrm{m})\end{array}$ & \\
\hline \multirow[t]{2}{*}{ 20-Story } & 1 & 50000 & 2000 & Box $150 \times 10$ \\
\hline & 2 & 50000 & 1000 & Box $150 \times 10$ \\
\hline \multirow[t]{2}{*}{ 30-Story } & 1 & 50000 & 2500 & Box $200 \times 10$ \\
\hline & 2,3 & 50000 & 1000 & Box $200 \times 10$ \\
\hline \multirow[t]{2}{*}{ 40-Story } & 1 & 50000 & 3500 & Box $200 \times 10$ \\
\hline & 2,3 & 50000 & 1500 & Box $200 \times 10$ \\
\hline
\end{tabular}

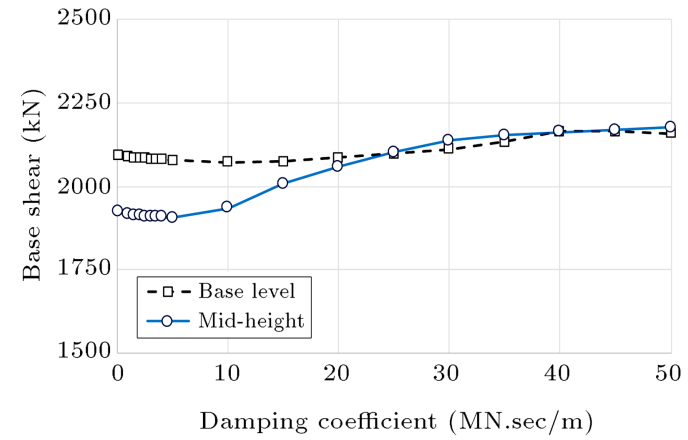

(a) 20-story structure

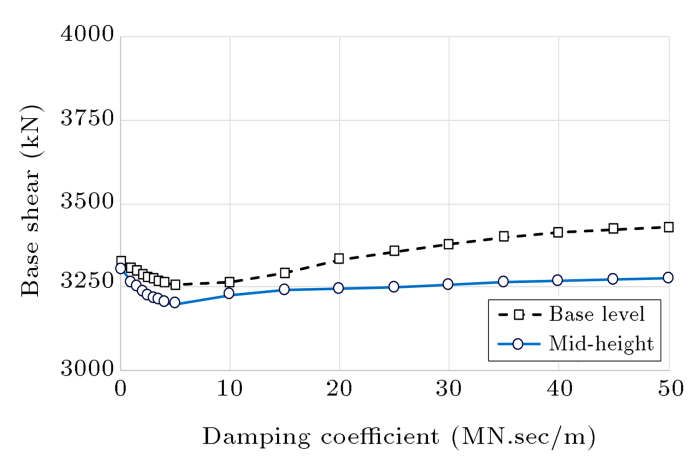

(b) 30-story structure

Figure 6. The effect of damping coefficient on base shear force for 20-story and 30-story structures subjected to Hector Mine earthquake.

at the roof level. Based on these assumptions, the designed section for steel brace element is selected according to the results of linear response spectrum analysis presented in Table 4 . Moreover, the damping coefficient $\left(C_{d}\right)$ is calculated by conducting nonlinear RHA at the design earthquake level. The effect of damping coefficient on the maximum seismic response of the damped outrigger system has been previously examined by some researchers $[10,16]$. Hence, it is necessary to iterate the viscous resistance $\left(C_{d}\right)$ of the dampers to determine its optimum value. The variation of base shear force with the damping coefficient for 20-story and 30-story structures subjected to Hector Mine earthquake is computed, as plotted in Figure 6. It can be seen that there is an optimum value for $C_{d}$ that can achieve the best performance. Moreover, the mid-height damped outrigger has better seismic performance than the damped outrigger case at the base level. This observation is in agreement with the results presented by Huang and Takeuchi [16]. The results of the parametric study calculated based on RHA lead to the optimum coefficient of viscous damper
(Table 4). Note that the damping exponent is assumed to be 1 , and the viscous damper behavior is linear.

\subsection{Studied positions for damped outriggers}

Several positions opted for damped outriggers in various cases including one, two, and three outriggers. In the one-outrigger case, the outrigger position moves upward along the height of the structure from the base. Thus, the number of cases analyzed in the structures with 20,30 , and 40 stories equals 10,15 , and 20, respectively. Determining the best position of damped outriggers, primarily in structures with more than one outrigger, involves a specific condition that is related to the outriggers arrangement. Therefore, in the two-outrigger case, it is assumed that one of these outriggers has been located in the lower half and the other one has been placed approximately at the upper half of the structure's height. For models equipped with three outriggers, the first outrigger is located at the lower one-third of the height, the position of the second outrigger varies at the middle one-third of the height, and the third outrigger is located at the 


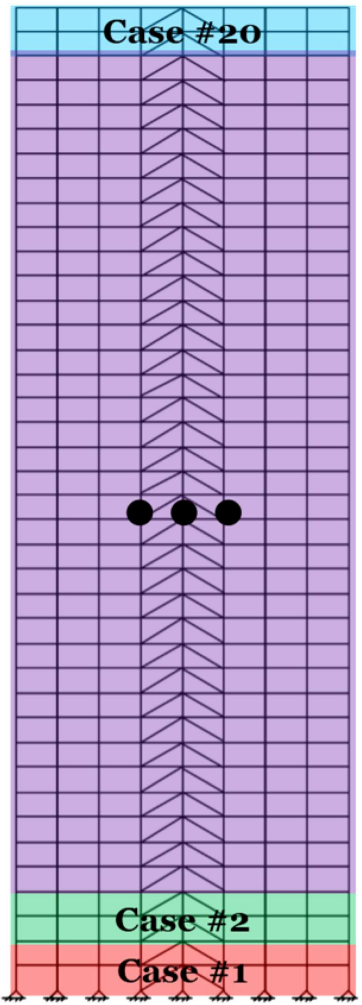

One-outrigger cases

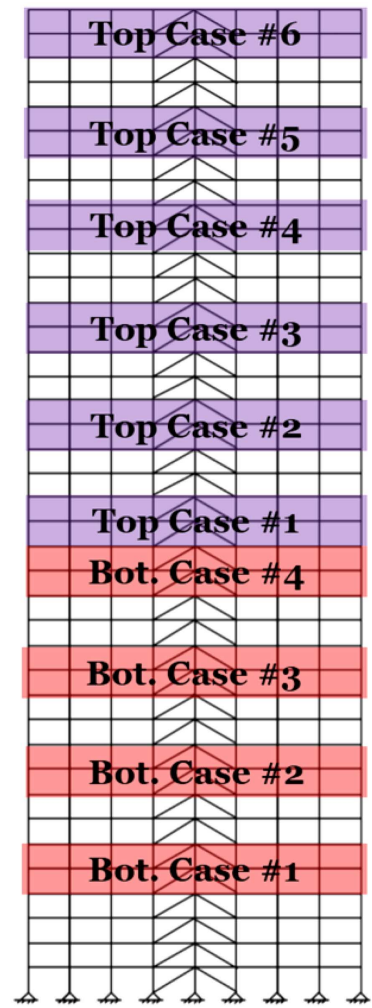

Two-outrigger cases

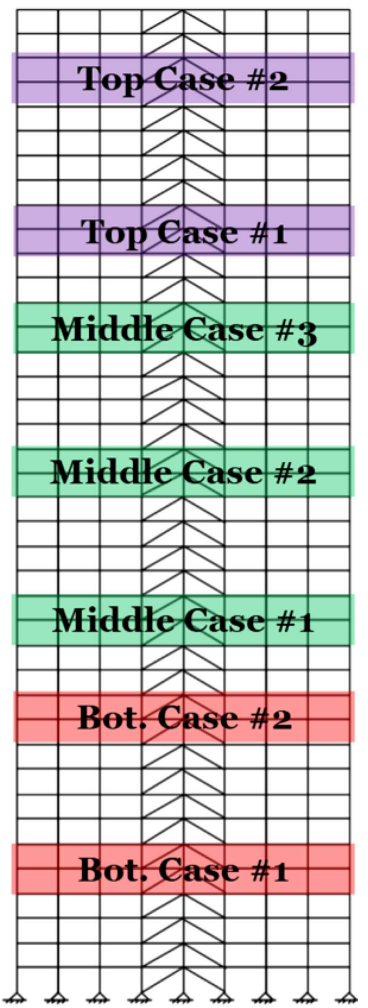

Three-outrigger cases

Figure 7. Studied positions of damped outriggers for the 40-story frame.

upper one-third of the building's height. This case is only considered for 30-story and 40-story models. For instance, these studied positions are illustrated for the 40-story structure in Figure 7.

\section{Optimum arrangement of damped outriggers}

\subsection{Definition of key parameters}

To investigate the performance of damped outrigger systems, two significant parameters composed of base shear force and inter-story drift ratio have been considered for determining the optimum arrangement of outriggers. The first parameter is the base shear force that can be demonstrated by the amount of lateral loads carried by the structural form. Interstory drift ratio is chosen as the second parameter, which is limited to definite values by guidelines. In order to evaluate predefined parameters, nonlinear RHA for each ground motion should be performed. The presented results include mean values of 8 earthquake ground motions. For all structures, this analysis is also performed without considering the effect of outriggers. As mentioned before, one-outrigger systems located at two adjacent stories labeled with their lower story numbers are depicted in the following figures. According to the ASCE/SEI 7-10 [21] for buildings with a long period, the allowable drift ratio is assumed to be equal to 0.02 .

\subsection{Base shear force}

The effect of maximum base shear force on the arrangement of damped outriggers is studied. For structures with one outrigger, the effect of outrigger location on the maximum base shear force is shown in Figure 8. It is found that the middle stories are the optimum positions for the damped outrigger in each model. The optimum location of the damped outrigger in the 30-story model is slightly higher than that of other structures due possibly to the greater aspect ratio. This conclusion is in agreement with the optimal outrigger location reported by Huang and Takeuchi [16] for three different outrigger frame buildings based on lateral displacement and story drift. It should be mentioned that the inter-story drift ratio is directly related to the resulting base shear of the structure for elastic systems.

In Figure 9, structures equipped with two outriggers are investigated. The results are reported in a way that the position of lower outrigger is fixed and the variation of maximum base shear force versus upper outrigger location is plotted. The results of each structural model are obtained as follows:

- For a 20-story frame, the optimum position of the 


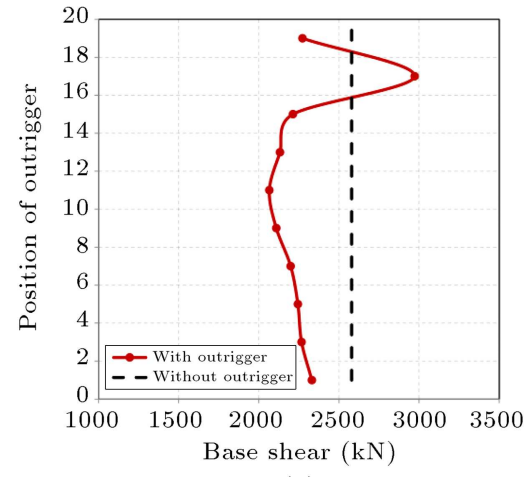

(a)

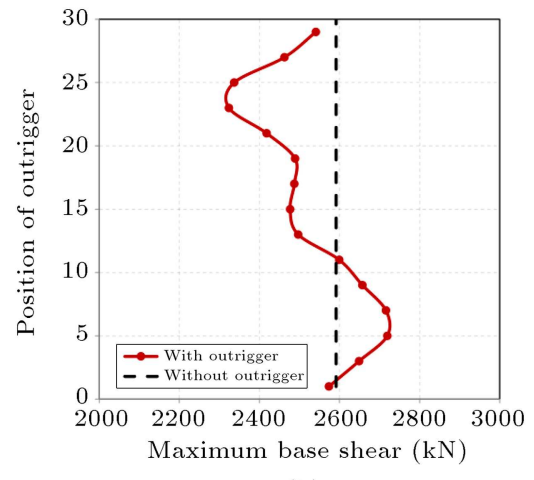

(b)

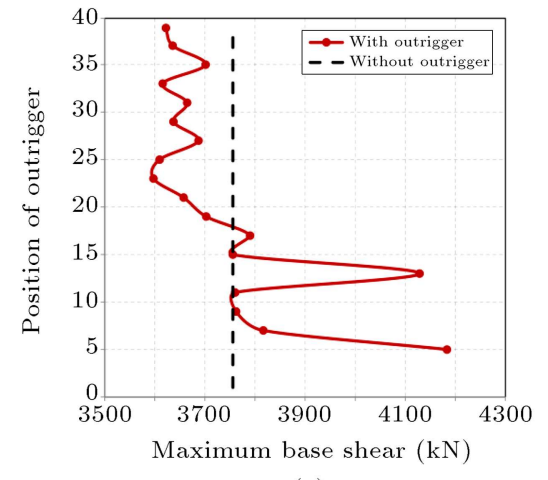

(c)

Figure 8. Effect of one damped outrigger location on the maximum base shear force (a) 20-story frame, (b) 30-story frame, and (c) 40-story frame.

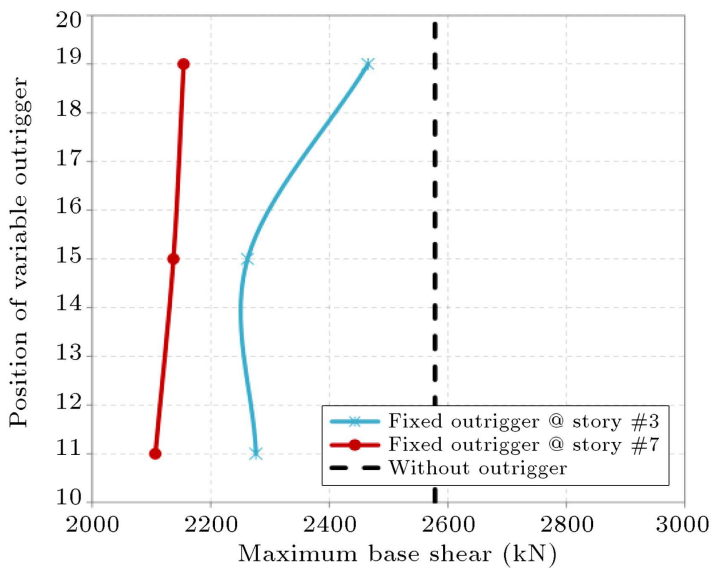

(a)

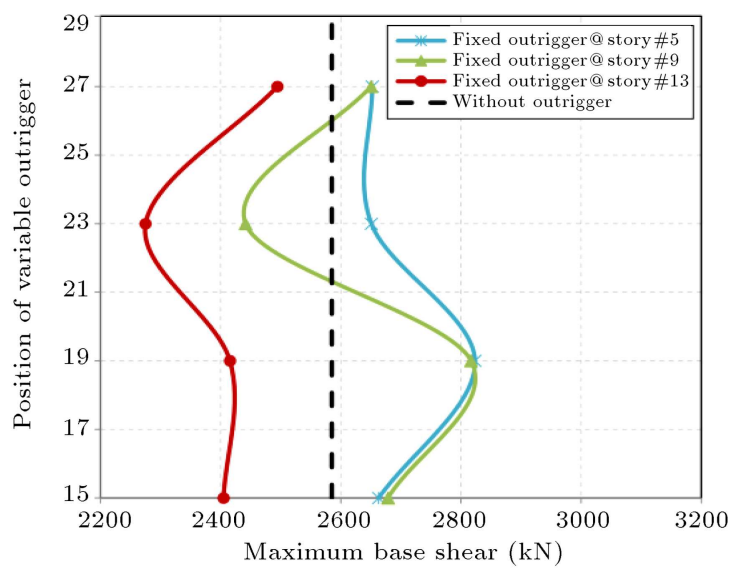

(b)

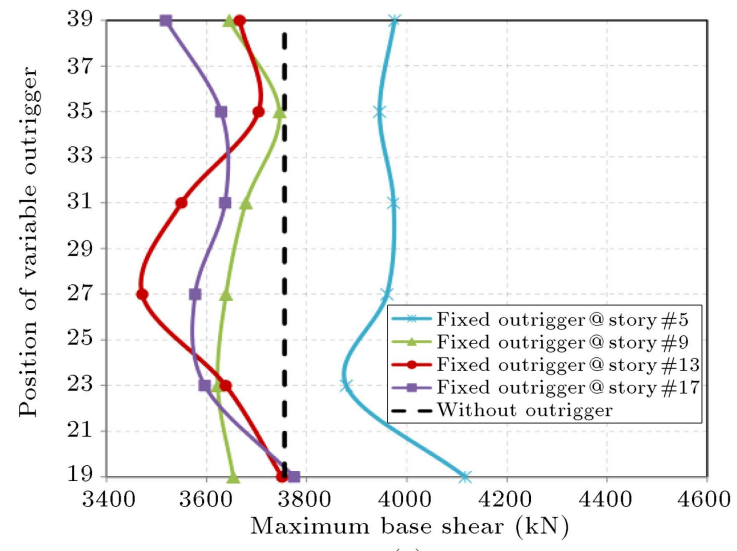

(c)

Figure 9. Effect of two damped outriggers' locations on the maximum base shear force (a) 20-story frame, (b) 30-story frame, and (c) 40-story frame.

lower outrigger is located at the 7 th story. Besides, the position of the upper outrigger has lower effect on minimizing base shear force. Therefore, it could be concluded that the application of two outriggers may not provide higher impressive efficiency than one outrigger in this structure;

- For other structures, the optimum positions of both lower and upper outriggers are approximately at 0.33 and 0.66 of the structural height, respectively;

- Note that similar to the one-outrigger case, two outriggers are placed slightly higher for the 30-story structure;

- It is observed that the optimal location of the lower outrigger is nearly at the mid-height when the upper 


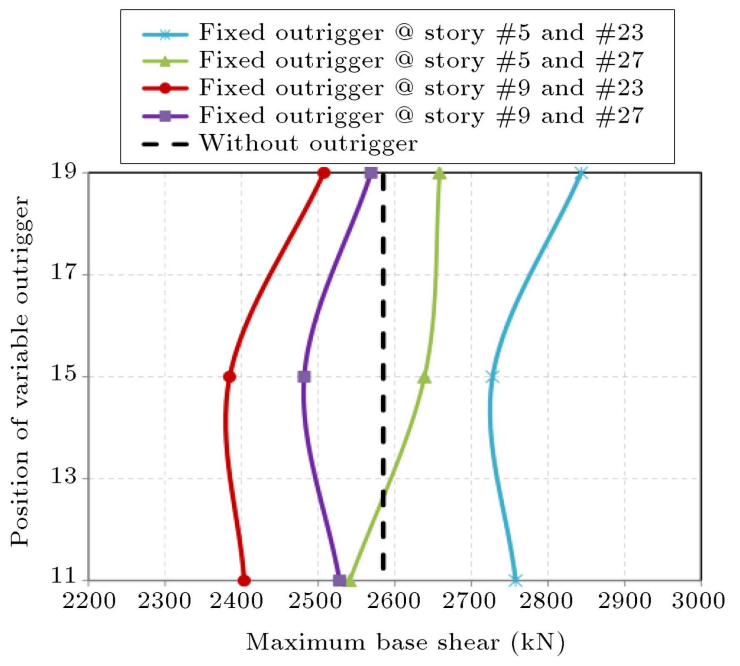

(a)

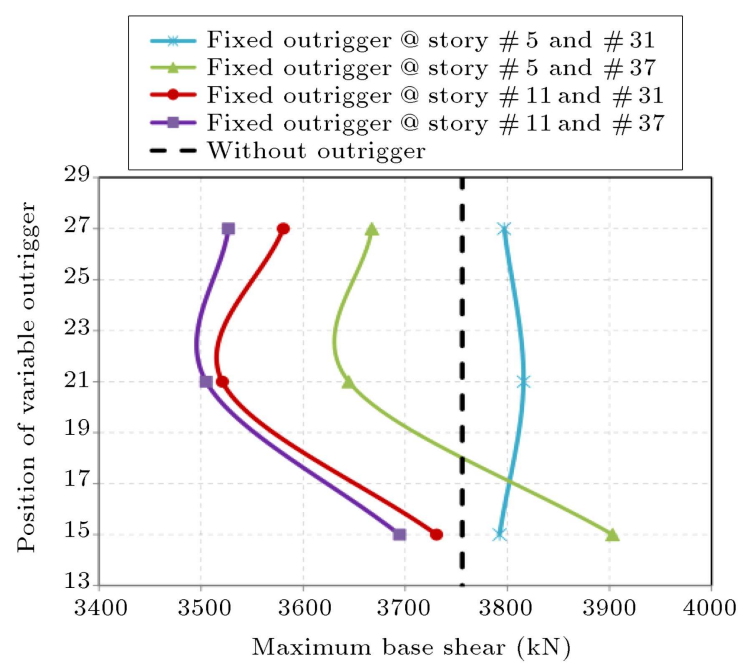

(b)

Figure 10. Effect of three damped outriggers' locations on the maximum base shear force: (a) 30-story frame and (b) 40-story frame.

outrigger is placed at the roof level. This trend is generally seen for all buildings with a different number of stories. This observation is compatible with the results of the study carried out by Fang et al. [15] for the maximum modal damping ratio of structures equipped with two damped outriggers.

Evidently, Figure 10 demonstrates the optimum positions of three outriggers. To determine the optimum positions of outriggers, it is assumed that the locations of upper and lower outriggers are fixed, and the base shear diagram is depicted versus the middle outrigger position. For a 30-story frame, the best positions of the first, second, and third outriggers are suggested to be at 9th, 15th, and 23rd stories, respectively. Further observations reveal that, in the three-outrigger case, the best locations of damped outriggers are nearly at $0.25,0.5$, and 0.75 of the structural height. Thus, the optimum location of damped outriggers based on minimizing the base shear force of the structure under seismic motion is similar to that of conventional outriggers.

\subsection{Inter-story drift ratio}

For the one-outrigger case, the variation of story drift ratio with the outrigger position is illustrated in Figure 11. It is seen that the drift ratio of bare structures increases along the height of structures. Therefore, story drift values of upper stories are more than those of the lower level. The performance of the damped outrigger system can be evaluated based on the amount of drift reduction. It is concluded that the addition of the damped outrigger to the models has a local effect. At the same time, it can also be observed that drift ratio decreases in stories placed near the damped outrigger. Although the application of a damped outrigger at the mid-height of the building has the most efficient effect because of minimizing the base shear force, this position does not provide the best condition for drift requirement. Furthermore, it is also found that placing a damped outrigger at the roof level provides the best condition for the story drift parameter.

The inter-story drift ratio of tall buildings with two outriggers is shown in Figure 12. It is observed that the application of one of the outriggers at the highest level has a drastic effect on the control of lateral deflections. Moreover, the appropriate position of the lower outrigger is at the middle stories. In a 20 -story structure, to reduce drift values, the optimum locations of the first and second outriggers include the 7 th and 19th stories. Therefore, the optimum positions of the lower and upper outriggers according to interstory drift are nearly at the mid-height of structure and roof level, respectively. It should be added that the efficiency of using two outriggers as opposed to one outrigger will be evaluated in the next section.

For structures with three outriggers, Figure 13 indicates the variation of story drift values versus the location of damped outriggers. It can be found that similar to previous cases, placing one outrigger at the top level of structure is highly efficient. For instance, the application of the upper outrigger at the 27th story has a good capability to decrease drift values of top stories of the 30-story frame.

\subsection{Optimum number of outriggers}

The optimum number of outriggers is obtained through the comparison of the responses of structures in various cases including one, two, and three outriggers. Figure 14 shows the variation of maximum base shear force along with the position and number of outriggers. It 


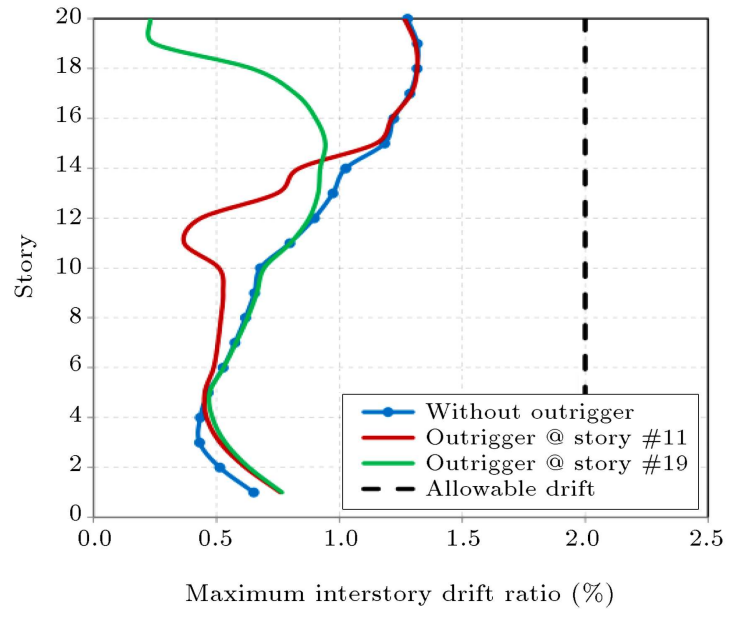

(a)

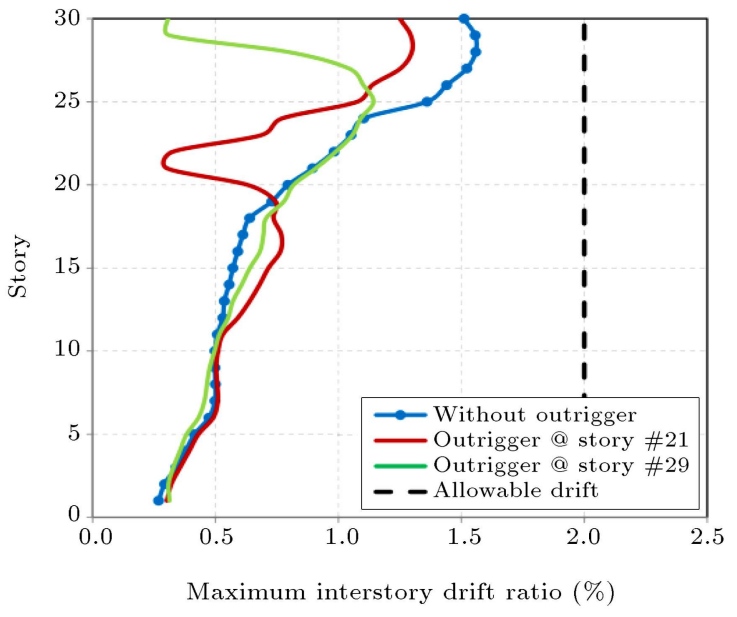

(b)

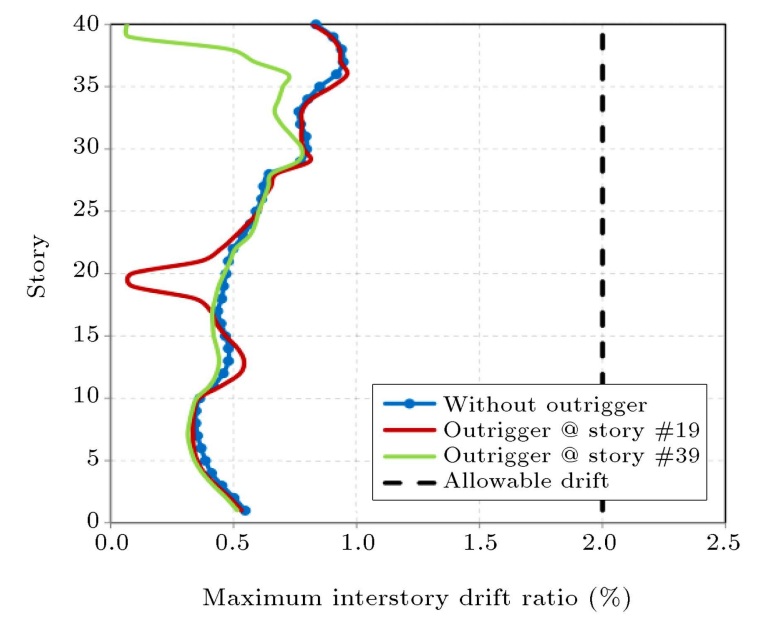

(c)

Figure 11. Effect of one damped outrigger's location on the inter-story drift ratio: (a) 20-story frame, (b) 30-story frame, and (c) 40-story frame.

is concluded that the optimum number of outriggers depends on the height of the building. In other words, as the number of stories and, consequently, the height of the structure increase, more outriggers are required. It is observed that the optimum number of outriggers to achieve the minimum base shear force in the 20-story structure is 1 . However, essentially, for the 40-story frame, the application of two outriggers provides an optimum condition. As observed earlier, the case of two damped outriggers for the 40-story structure leads to lower base shear force than the case of the single damped outrigger. This finding was confirmed by Fang et al. [15].

To determine the optimum number of outriggers according to inter-story drift requirement, Figure 15 should be considered. It is also found that, in this case, similar to the base shear parameter, the optimum number of outriggers for the 20-story frame is 1 , whereas, for a 40-story structure, two outriggers are needed. In the two-outrigger case, it is recommended that one of those outriggers should be located at the roof level to achieve good efficiency of story drifts, as mentioned earlier in this paper.

\subsection{Hysteretic behavior of damper and steel members}

The force-displacement hysteretic curve of the damper element for the 30-story structure subjected to Manjil earthquake is seen in Figure 16. The results are for systems with one damped outrigger at two positions and the case of two damped outriggers located at the 13 th and 23th stories. It is observed that the viscous damper in the case of the outrigger placed at midheight dissipates greater seismic energy, which implies that the damper is working efficiently. For the case of two damped outriggers, the energy dissipated by lower and upper outriggers is also depicted in Figure 16. As observed earlier, both dampers have almost the same hysteretic performances.

Furthermore, the damped outrigger system can 


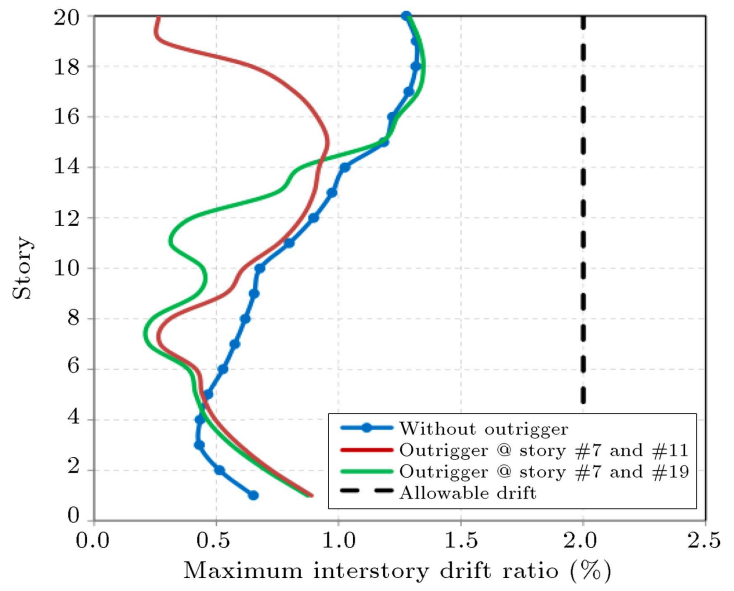

(a)

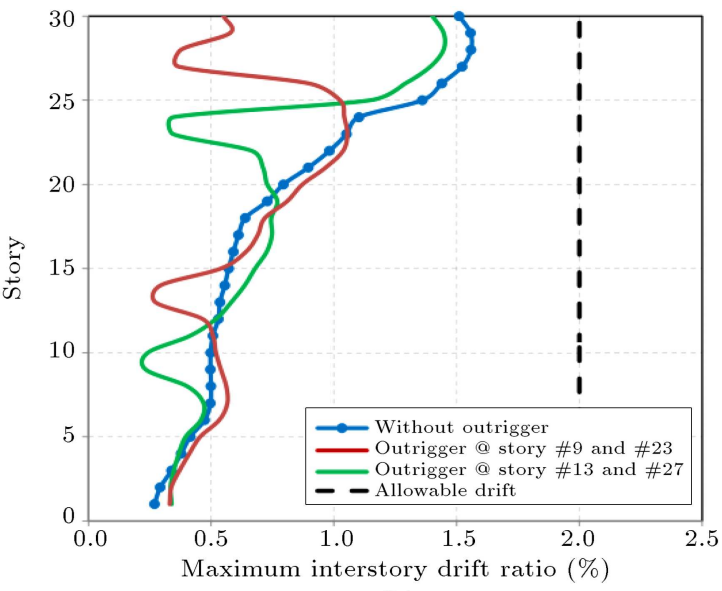

(b)

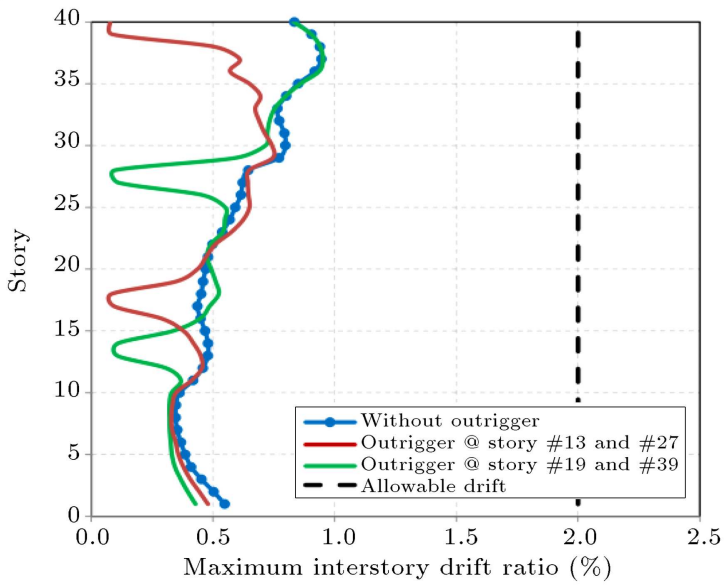

(c)

Figure 12. Effect of two damped outriggers' locations on the inter-story drift ratio: (a) 20-story frame, (b) 30-story frame, and (c) 40-story frame.

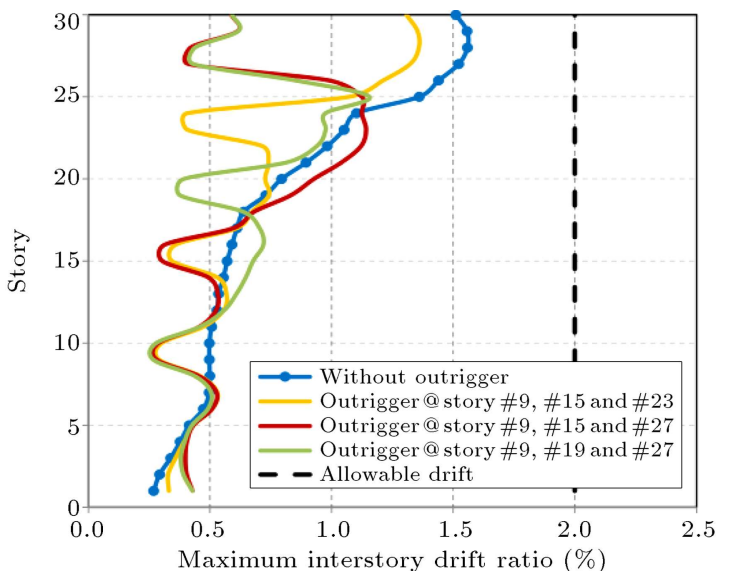

(a)

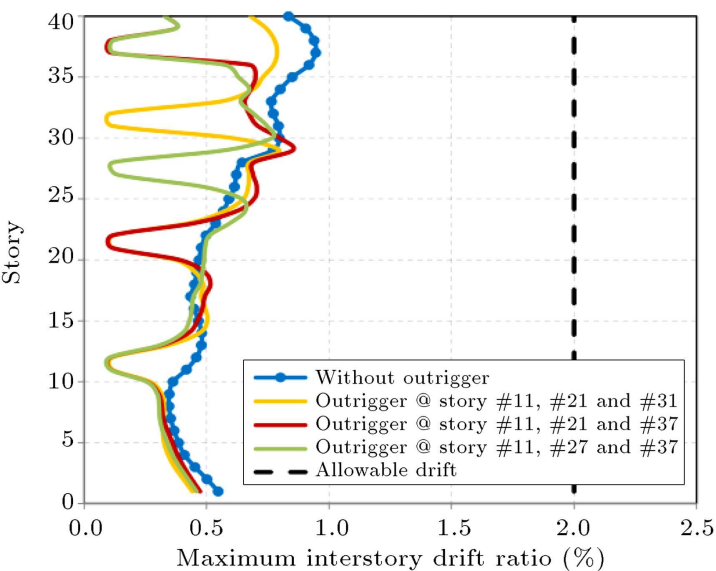

(b)

Figure 13. Effect of three damped outriggers' locations on the inter-story drift ratio: (a) 30-story frame and (b) 40-story frame.

significantly mitigate seismic demand and damage to the main structural components. Figure 17 shows the effect of damped outrigger on the hysteretic behavior of the 25 th story brace and the 29th story exterior beam. The results corresponding to the 30 -story structure with one damped outrigger at mid-height subjected to Manjil ground motion are plotted in comparison with the intact model. It can be observed that, under the optimal outrigger arrangement, the addition of viscous dampers decreases both the seismic displacement de- 


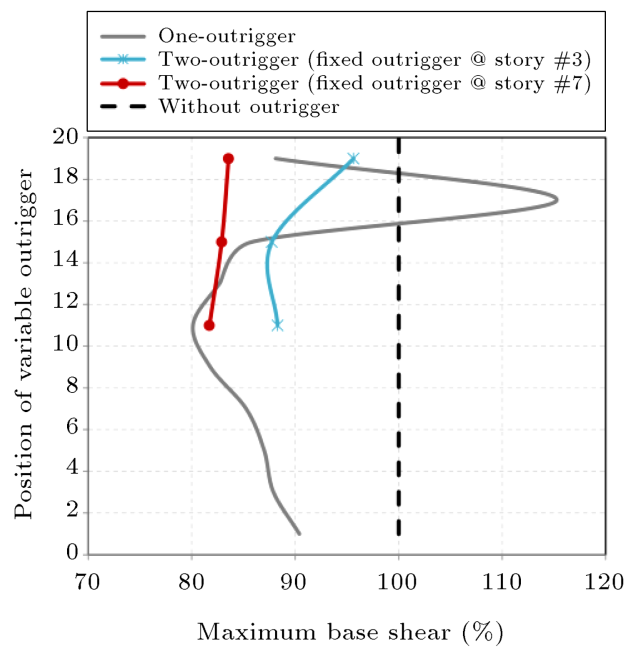

(a)

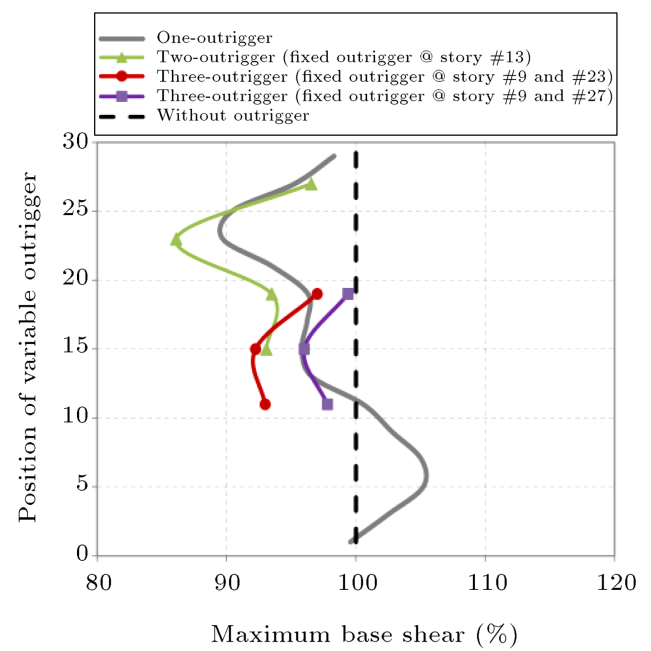

(b)

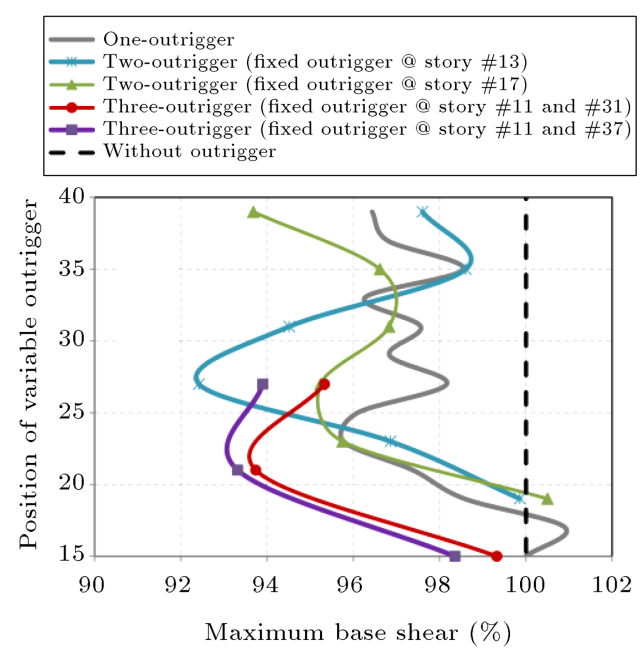

(c)

Figure 14. Optimum number of damped outriggers according to base shear force: (a) 20-story frame, (b) 30-story frame, and (c) 40-story frame.

mand of exterior beam and core brace element, leading to the increase of the seismic performance level of the damped outrigger systems with respect to the intact model.

\section{Conclusions}

This paper investigated the effect of damped outriggers arrangement on the base shear force and the inter-story drift ratio of high-rise structures. For this purpose, three models involving 20-story, 30-story, and 40-story cases are presented. A preliminary design of these models was performed by the linear response spectrum analysis to satisfy the requirements of Iranian National Buildings Codes. The deficiency observed in the initial design procedure decreased by adding damped outriggers to the structures. Eight ground motions were applied to obtain the nonlinear seismic response of tall buildings. The main conclusions of this study can be summarized as follows:

1. The optimum location of damped outriggers for minimizing base shear force under seismic excitation was mainly the same as that obtained for conventional outriggers statically loaded;

2. Placing the outrigger at the highest level had a significant effect on the control of lateral deflections;

3. The efficiency of viscous dampers in the case of damped outrigger at the mid-height was better than the case of damped outrigger at the base level;

4. The optimum number of damped outriggers was dependent on the height of the structure. Accordingly, the number of required outriggers increased with the building height;

5. The damping coefficient of the outriggers affected 


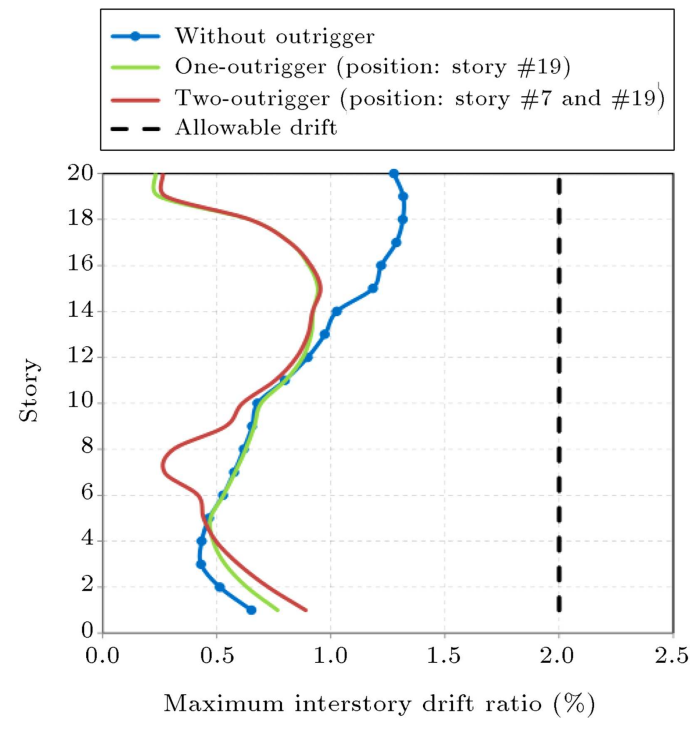

(a)

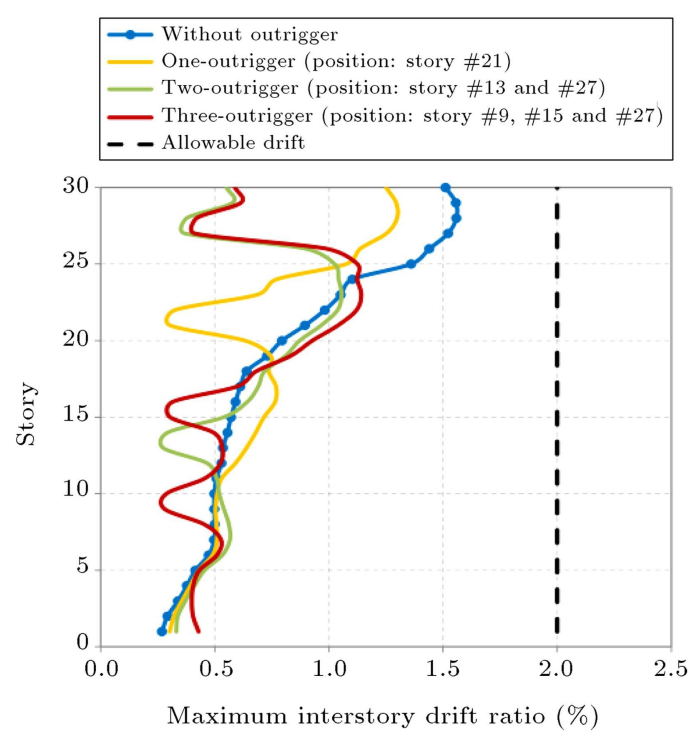

(b)

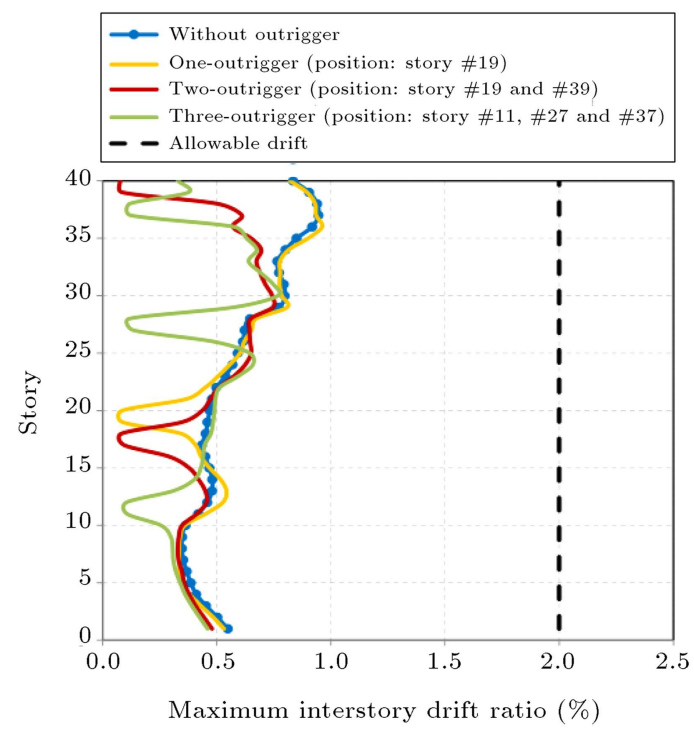

(c)

Figure 15. Optimum number of damped outriggers according to inter-story drift ratio: (a) 20-story frame, (b) 30-story frame, and (c) 40-story frame.

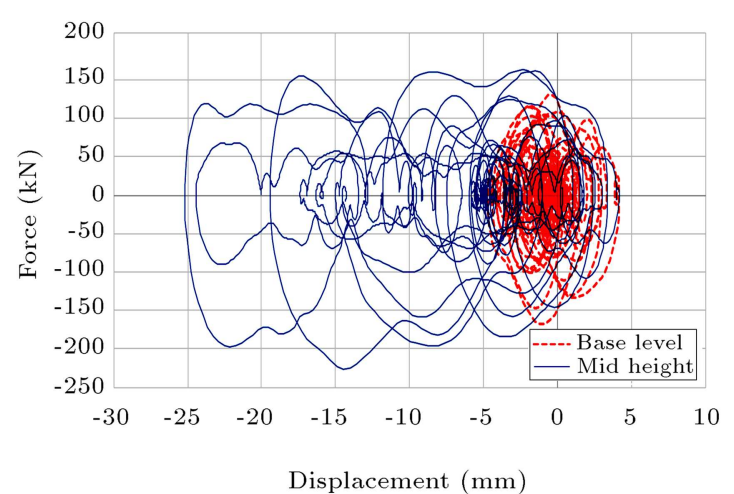

(a) One damped outrigger

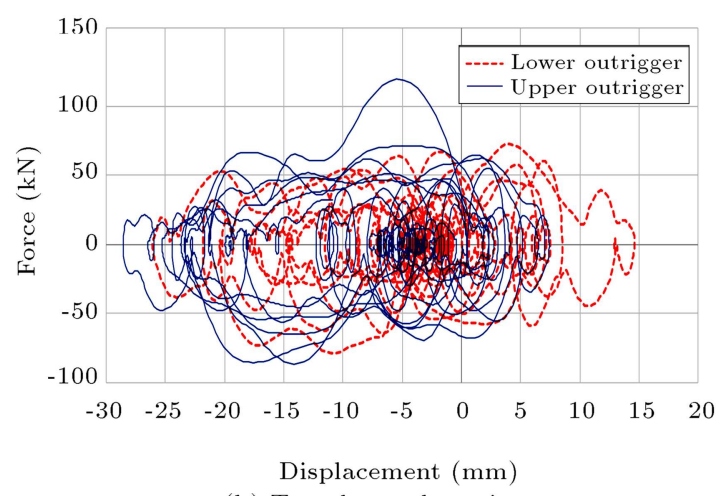

(b) Two damped outriggers (at 13 th story and 23 th story)

Figure 16. Hysteretic curve of viscous dampers for the 30-story structure under Manjil earthquake. 


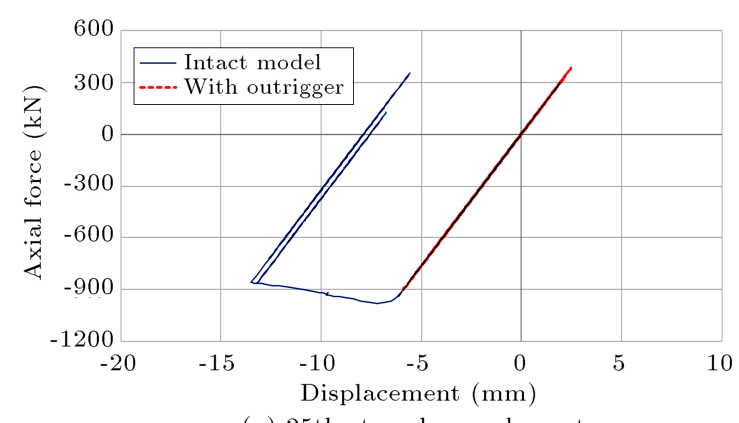

(a) 25th story-brace element

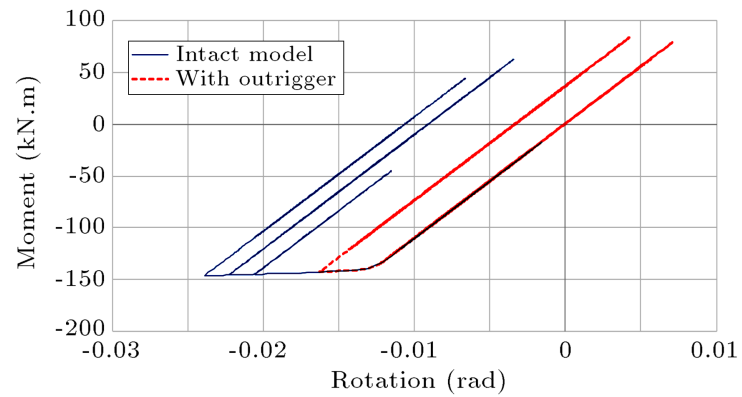

(b) 29 th story-exterior beam span (left side)

Figure 17. The effect of damped outrigger on the hysteretic behavior of brace and beam members.

the seismic response of the structures. Consequently, it must be adjusted to an appropriate value.

\section{References}

1. Stafford Smith, B. and Coull, A., Tall Building Structures: Analysis and Design, John Wiley \& Sons, New York (1991).

2. Choi, H., Ho, G., Joseph, L., and Mathias, N., Outrigger Design for High-Rise Buildings: An Output of the CTBUH Outrigger Working Group, Council on Tall Buildings and Urban Habitat, Chicago (2012).

3. Applied Technology Council, Modeling and Acceptance Criteria for Seismic Design and Analysis of Tall Buildings, PEER/ATC-72-1, Prepared for Pacific Earthquake Engineering Research Center (PEER), California (2010).

4. Smith, R.J. and Willford, M.R. "Damped outriggers for tall buildings", The ARUP Journal, 3, pp. 15-21 (2008).

5. Taranath, B.S. "Optimum belt truss locations for highrise structures", AISC Engineering Journal, 11(1), pp. 18-21 (1974).

6. McNabb, J.W. and Muvdi, B.B. "Drift reduction factors for belted high-rise structures", Engineering Journal, American Institute of Steel Construction, 12, pp. 88-91 (1975).

7. Rutenberg, A. and Tal, D. "Lateral load response of belted tall building structures", Engineering Structures, 9(1), pp. 53-67 (1987).

8. Stafford Smith, B. and Salim, I. "Parameter study of outrigger-braced tall building structures", Journal of the Structural Division, 107(10), pp. 2001-2014 (1981).

9. Wu, J.R. and Li, Q.S. "Structural performance of multi-outrigger-braced tall buildings", The Structural Design of Tall and Special Buildings, 12(2), pp. 155176 (2003).

10. Smith, R.J. and Willford, M.R. "The damped outrigger concept for tall buildings", The Structural Design of Tall and Special Buildings, 16(4), pp. 501-517 (2007).
11. Zhou, Y. and Li, H. "Analysis of a high-rise steel structure with viscous damped outriggers", The Structural Design of Tall and Special Buildings, 23(13), pp. 963979 (2014).

12. Deng, K., Pan, P., Lam, A., and Xue, Y. "A simplified model for analysis of high-rise buildings equipped with hysteresis damped outriggers", The Structural Design of Tall and Special Buildings, 23(15), pp. 1158-1170 (2014).

13. Chen, Y., McFarland, D.M., Wang, Z., Spencer Jr, B.F., and Bergman, L.A. "Analysis of tall buildings with damped outriggers", Journal of Structural Engineering, 115(4), pp. 1435-1443 (2013).

14. Tan, P., Fang, C., and Zhou, F. "Dynamic characteristics of a novel damped outrigger system", Earthquake Engineering and Engineering Vibration, 13(2), pp. 293-304 (2014).

15. Fang, C.J., Tan, P., Chang, C.M., and Zhou, F.L. "A general solution for performance evaluation of a tall building with multiple damped and undamped outriggers", The Structural Design of Tall and Special Buildings, 24(12), pp. 797-820 (2015).

16. Huang, B. and Takeuchi, T. "Dynamic response evaluation of damped-outrigger systems with various heights", Earthquake Spectra, 33(2), pp. 665-685 (2017).

17. Morales-Beltran, M., Turan, G., Yildirim, U., and Paul, J. "Distribution of strong earthquake input energy in tall buildings equipped with damped outriggers", The Structural Design of Tall and Special Buildings, 27(8), e1463 (2018).

18. Youssef, N., Wilkerson, R., Fischer, K., and Tunick, D. "Seismic performance of a 55-storey steel plate shear wall", The Structural Design of Tall and Special Buildings, 19(1-2), pp. 139-165 (2010).

19. Beiraghi, H., Kheyroddin, A., and Kafi, M.A. "Effect of record scaling on the behavior of reinforced concrete core-wall buildings subjected to near-fault and farfault earthquakes", Scientia Iranica, A, 24(3), pp. 884-899 (2017).

20. Beiraghi, H. and Siahpolo, N. "Seismic assessment of RC core-wall building capable of three plastic hinges with outrigger", The Structural Design of Tall and Special Buildings, 26(2), e1306 (2017). 
21. Beiraghi, H. "Near-fault ground motion effects on the responses of tall reinforced concrete walls with buckling-restrained brace outriggers", Scientia Iranica, 25(4), pp. 1987-1999 (2018).

22. American Institute of Steel Construction, Specification for Structural Steel Buildings, ANSI/AISC 360-10, Chicago, IL (2010).

23. American Institute of Steel Construction, Seismic Provisions for Structural Steel Buildings, ANSI/AISC 341-10, Chicago, IL (2010).

24. American Society of Civil Engineers, Minimum Design Loads for Buildings and Other Structures, ASCE/SEI 7-10, New York (2010).

25. OpenSees (Open System for Earthquake Engineering Simulation platform), Version 2.4.0, developed by the Pacific Earthquake Engineering Research Center (PEER), Berkeley, http://opensees.berkeley.edu/

26. Uriz, P. and Mahin, S.A. "Toward earthquake-resistant design of concentrically braced steel-frame structures", Report No. 2008/08, Pacific Earthquake Engineering Research Center (PEER), College of Engineering, University of California, Berkeley (2008).

27. SeismoSoft. SeismoStruct: A computer program for static and dynamic nonlinear analysis of framed structures (online), available from URL: http:// seismosoft.com/

28. Federal Emergency Management Agency (FEMA),
Improvement of Nonlinear Static Seismic Analysis Procedures, FEMA-440, Washington, D.C. (2005).

29. Federal Emergency Management Agency (FEMA), Quantification of Building Seismic Performance Factors, FEMA P695, Washington, D.C. (2009).

30. Pacific Earthquake Engineering Research Center (PEER), PEER Strong Motion Database, http://peer. berkeley.edu/smcat/.

\section{Biographies}

Hamid Asadi Ghoozhdi is a PhD Candidate from University of Tehran. He received his MSc degrees in Structural Engineering from the Sharif University of Technology and BSc degree in Civil Engineering from Ferdowsi University of Mashhad. His research interests lie in the field of performance-based seismic design of tall buildings, soil-structure interaction problems, and seismic bridge design.

Masood Mofid is a Professor at the Civil Engineering Department at Sharif University of Technology. He earned his BSc degree from the University of Tehran, Tehran, Iran. Moreover, he received his MSc and PhD degrees from Rice University. His research applies the principles of structural dynamics and engineering mechanics. 